\title{
Demonstration of increased concentrations of circulating glycated insulin in human Type 2 diabetes using a novel and specific radioimmunoassay
}

\author{
J. R. Lindsay' ${ }^{1}$, A. M. McKillop ${ }^{2}$, M. H. Mooney ${ }^{2}$, F. P. M. O’Harte' ${ }^{2}$, P. M. Bell ${ }^{1}$, P. R. Flatt ${ }^{2}$ \\ ${ }^{1}$ Regional Centre for Endocrinology, Royal Victoria Hospital, Belfast, Northern Ireland, UK \\ ${ }^{2}$ School of Biomedical Sciences, University of Ulster, Coleraine, County Londonderry, Northern Ireland, UK
}

\begin{abstract}
Aims/hypothesis. Glycation of insulin, resulting in impaired bioactivity, has been shown within pancreatic beta cells. We have used a novel and specific radioimmunoassay to detect glycated insulin in plasma of Type 2 diabetic subjects.

Methods. Blood samples were collected from 102 Type 2 diabetic patients in three main categories: those with good glycaemic control with a $\mathrm{HbA}_{1 \mathrm{c}}$ less than $7 \%$, moderate glycaemic control $\left(\mathrm{HbA}_{1 \mathrm{c}} 7-9 \%\right)$ and poor glycaemic control $\left(\mathrm{HBA}_{1 \mathrm{c}}\right.$ greater than $\left.9 \%\right)$. We used 75 age- and sex-matched non-diabetic subjects as controls. Samples were analysed for $\mathrm{HbA}_{1 \mathrm{c}}$, glucose and plasma concentrations of glycated insulin and insulin.
\end{abstract}

Results. Glycated insulin was readily detected in control and Type 2 diabetic subjects. The mean circulating concentration of glycated insulin in control subjects was $12.6 \pm 0.9 \mathrm{pmol} / \mathrm{l}(n=75)$. Glycated insulin in the good, moderate and poorly controlled diabetic groups was increased 2.4-fold $(p<0.001, n=44), 2.2$ fold $(p<0.001, n=41)$ and 1.1-fold $(n=17)$ corresponding to $29.8 \pm 5.4,27.3 \pm 5.7$ and $13.5 \pm 2.9 \mathrm{pmol} / \mathrm{l}$, respectively.

Conclusion/interpretation. Glycated insulin circulates at noticeably increased concentrations in Type 2 diabetic subjects. [Diabetologia (2003) 46:475-478]

Keywords Glycated insulin, glucose toxicity, Type 2 diabetes.
Formation of advanced glycation-end products (AGEs) plays an important role in long-term metabolic consequences of diabetes including ophthalmic, renal and atherosclerotic vascular complications. Glycation has been shown also to interfere with normal cellular functions including the activities of various enzymes such as $\mathrm{Cu}-\mathrm{Zn}$ superoxide dismutase and several other peptide hormones. A growing body of evidence now exists to support the hypothesis that glycation of insulin in pancreatic beta cells occurs under conditions of hyperglycaemia. Glycated insulin has been identified in the pancreas of normal and diabetic animal models

Received: 27 September 2002 / Revised: 27 December 2002 Published online: 18 March 2003

CC Springer-Verlag 2003

Corresponding author: F. P. M. O'Harte, School of Biomedical Sciences, University of Ulster, Coleraine, County Londonderry, BT52 1SA, Northern Ireland, UK

E-mail: fpm.oharte@ulster.ac.uk
[1]; the process of glycation in the beta cell is rapid and occurs in a time- and concentration-dependent manner [2]. Previous studies have shown that glycated insulin has a reduced ability to regulate plasma glucose homeostasis in vivo and to stimulate adipose tissue lipogenesis or glucose uptake and oxidation by isolated diaphragm and abdominal muscle in vitro [3, $4,5]$. Studies in healthy human volunteers using the hyperinsulinaemic-euglycaemic glucose clamp technique suggest that glycated insulin could contribute to insulin resistance in Type 2 diabetes mellitus [6].

The site of glycation of human insulin has now been identified by electrospray tandem mass spectrometry as the N-terminal $\mathrm{Phe}^{1}$ of the B-chain [7], enabling the development of a sensitive and specific radioimmunoassay to measure concentrations of glycated insulin and to identify glycated insulin in pancreatic islets using immunohistochemistry [8]. High performance liquid chromatography techniques used previously were neither sensitive nor reliable 
Table 1. Characteristics of controls subjects and Type 2 diabetic patients

\begin{tabular}{lllll}
\hline & Control subjects & $\begin{array}{l}\text { Patients with } \\
\text { good control }\end{array}$ & $\begin{array}{l}\text { Patients with } \\
\text { moderate control }\end{array}$ & $\begin{array}{c}\text { Patients with } \\
\text { poor control }\end{array}$ \\
\hline Number of subjects & 75 & 44 & 41 & 17 \\
Male/female ratio & $31 / 44$ & $21 / 23$ & $24 / 17$ & $9 / 8$ \\
Age (years) & $59.5 \pm 2.1$ & $64.6 \pm 1.4$ & $63.4 \pm 1.7$ & $61.0 \pm 3.7$ \\
Duration of diabetes (years) & - & $4.8 \pm 0.6$ & $7.1 \pm 0.9$ & $8.5 \pm 1.3$ \\
BMI $\left(\mathrm{kg} / \mathrm{m}^{2}\right.$ ) & $25.6 \pm 0.5$ & $29.6 \pm 1.0 * * *$ & $30.6 \pm 1.0^{* * *}$ & $28.9 \pm 1.3^{* *}$ \\
Serum Creatinine $(\mu \mathrm{mol} / \mathrm{l})$ & $86.0 \pm 4.0$ & $89.2 \pm 3.6$ & $89.0 \pm 4.0$ & $85.8 \pm 3.6$ \\
Diet $(\%)$ & - & 40.9 & 26.8 & 17.6 \\
Metformin $(\%)$ & - & 18.2 & 14.6 & 11.8 \\
Sulphonylureas $(\%)$ & - & 29.5 & 26.8 & 17.6 \\
Metformin/Sulphonyureas $(\%)$ & - & 6.8 & 26.8 & 47.1 \\
Other drug combinations $(\%)^{\mathrm{a}}$ & - & 4.6 & 4.9 & 5.9 \\
\hline
\end{tabular}

Values are means \pm SEM. $* * p<0.01 * * * p<0.001$ compared with control subjects. ${ }^{\text {a }}$ Other treatment combinations included metformin and acarbose, gliclazide and acarbose and glibenclamide and acarbose

enough to measure circulating glycated insulin in normal or diabetic states. This paper describes the use of a sensitive and specific radioimmunoassay to measure increased concentrations of glycated insulin in the plasma of patients with Type 2 diabetes mellitus.

\section{Subjects and methods}

Subjects. Mid-morning blood samples were taken from Type 2 diabetic subjects $(n=102)$. All subjects were controlled by diet alone or by oral hypoglycaemic agents. No subjects were receiving insulin. Type 2 diabetic subjects were divided into three groups depending upon their glycaemic control. Group 1 represented subjects under good glycaemic control with a $\mathrm{HbA}_{1 \mathrm{c}}$ less than $7 \%$. Group 2 was comprised of subjects with moderate glycaemic control $\left(\mathrm{HbA}_{1 \mathrm{c}} 7-9 \%\right)$ and Group 3 represented subjects with a $\mathrm{HbA}_{1 \mathrm{c}}$ greater than $9 \%$ (poor glycaemic control). Age- and sex-matched normal healthy individuals served as controls. This study was approved by the ethics committee of The Queen's University of Belfast and all subjects gave their written informed consent.

Biochemical analyses. Development of a specific RIA for glycated insulin has been described in detail elsewhere [8]. In brief, an N-terminally glycated synthetic insulin peptide, closely related to the amino-terminal sequence of the insulin B-chain (Phe-Val-Asn-Gln-His-Leu-Tyr-Lys) was used to raise specific antibodies in rabbits. Antiserum R3/B/vi was used to establish a dextran-coated charcoal RIA with a glycated human insulin standard curve containing insulin free serum. Assay sensitivity was less than $3 \mathrm{pmol} / \mathrm{l}$ with an intra-assay coefficient of variation of $9 \%$. The glycated insulin antibody crossreacted $56 \%$ with glycated proinsulin but cross-reaction with non-glycated insulin, proinsulin and other pancreatic hormones was negligible [8]. Serum insulin was determined using a microparticulate enzyme immunoassay. Assay sensitivity was less than $6 \mathrm{pmol} / \mathrm{l}$ with an intra-assay coefficient of variation of $4 \%$. Cross-reactivity with proinsulin and split products was less than $0.01 \%$ with no detectable reaction with proinsulin C-peptide. Restricted cross-reaction was observed with glycated insulin corresponding to approximately 50\%. Glucose concentrations, $\mathrm{HbA}_{1 \mathrm{c}}$ and creatinine were determined by conventional assays.
Statistical analysis. Data are expressed as means \pm SEM. Significant differences between groups of data were assessed using the unpaired Student's $t$ test and a $p$ value of less than 0.05 was considered statistically significant.

\section{Results}

Control and diabetic groups were matched for age, sex, creatinine and BMI (Table 1). Duration of diabetes increased progressively from good, moderate to poorly controlled groups. A total of 70 diabetic subjects were taking oral hypoglycaemics of whom 16 were taking metformin alone, 27 sulphonylurea alone and 22 were taking a combination of metformin and sulphonylurea. The remaining patients were treated with dietary restriction alone, or a combination of other treatments, which included acarbose.

Control subjects had mean glycated haemoglobin values of $5.7 \pm 0.1 \%$ compared with $6.4 \pm 0.1(p<0.001)$, $7.9 \pm 0.1(p<0.001)$ and $10.4 \pm 0.4 \%(p<0.001)$ for good, moderate and poorly controlled diabetic groups, respectively. Plasma glucose concentrations were similarly raised in the diabetic groups, with highest values observed in the poorly controlled group (Fig. 1). A positive correlation between glycated haemoglobin and glucose concentration was evident in the combined groups $(r=0.322 ; p<0.01)$. Plasma glycated insulin concentrations of good and moderately controlled diabetic groups were increased 2.4-fold $(p<0.001)$ and 2.2-fold $(p<0.001)$ compared with control subjects (Fig. 1). Plasma glycated insulin concentrations in the control group, well, moderately and poorly controlled diabetic groups were $12.8 \pm 1.1$ (SD 9.2), 29.8 \pm 5.4 (SD 35.7), 27.3 \pm 5.7 (SD 36.5) and $13.5 \pm 2.9$ (SD 11.9) pmol/l, respectively. The glycated insulin concentrations of the poorly controlled group were not noticeably increased and no correlation was found in the combined groups between glycated insulin and either glycated haemoglobin or plasma glucose 

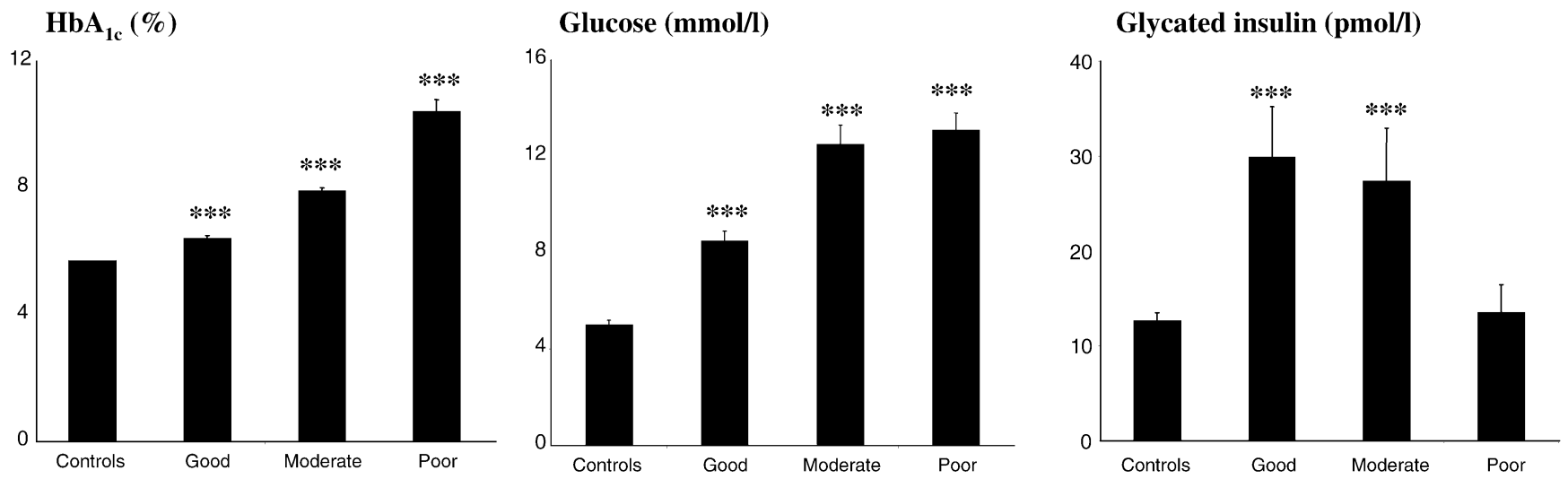

Fig. 1. $\mathrm{HbA}_{1 \mathrm{c}}$, plasma glucose and glycated insulin concentrations of control subjects and diabetic patients with good, moderate or poor metabolic control. Values are means \pm SEM. $* * * p<0.001$ compared with control subjects

concentrations (data not shown). Glycated insulin was found to circulate at $26.1 \pm 2.9 \mathrm{pmol} / 1$ in the combined groups $(p<0.001$, compared with controls). Insulin concentrations measured using a specific insulin antiserum in the control, good, moderate and poorly controlled groups were $148 \pm 19,191 \pm 25,225 \pm 40$ and $159 \pm 40 \mathrm{pmol} / \mathrm{l}$, respectively.

\section{Discussion}

Disturbances of insulin secretion and peripheral insulin action are well-described features of Type 2 diabetes mellitus, and a growing body of data support the role of glycation of insulin as a feature of beta-cell dysfunction and insulin resistance. Evidence includes the demonstration of increased concentrations of glycated insulin in the pancreas of various animal models of diabetes $[1,8,9]$ and the time- and concentration-dependent glycation of insulin in both isolated mouse islets or clonal insulin secreting cell lines under hyperglycaemic conditions $[1,2]$. We have previously shown the impaired biological activity of glycated insulin using in vitro studies with isolated muscle preparations and in vivo studies using animal models or healthy human subjects subjected to hyperinsulinaemic euglycaemic glucose clamps $[3,4,5,6]$. Having identified the site of glycation of insulin as the amino terminal $\mathrm{Phe}^{1}$ residue of the insulin B-chain [7], a novel, sensitive and specific radioimmunoassay has recently been developed to detect glycated insulin in plasma and biological tissues [8].

In this study, we have examined circulating glycated insulin using this radioimmunoassay in 102 Type 2 diabetic patients, classified into good, moderate and poorly controlled groups, in comparison with age- and sex-matched control subjects. The results readily indicate that glycated insulin circulates at increased concentrations in Type 2 diabetic patients with increases

of 2.4-fold, 2.2-fold and 1.1-fold in the three diabetic subgroups, respectively. These results corroborate a recent study which determined raised concentrations of glycated insulin in the plasma of various animal models of Type 2 diabetes [8,9]. Individual variations of glycated insulin in subjects from the various groups possibly reflect the collection of a single fasted sample together with possible individual differences in beta-cell secretory activity, diet history and duration of diabetes. However, it is clear from these observations that the concentration of insulin circulating in the glycated form in diabetes is significant compared with control subjects. Estimation of the precise proportion of glycated insulin relative to insulin is not possible at the moment due to differences in the cross-reactivity of the antisera with proinsulin or glycated proinsulinderived peptides. The amounts of circulating proinsulin and split products are also likely to vary between the four observation groups.

We had initially anticipated increased concentrations of plasma glycated insulin in the most poorly controlled diabetic subjects in keeping with a time and concentration dependent glycation process in the pancreatic beta cell [2]. However this group showed relatively reduced concentrations of circulating plasma glycated insulin and insulin compared to the higher concentrations in the good and moderately controlled diabetic groups. Thus whereas a noticeable correlation existed between plasma glucose and glycated haemoglobin, concentrations of glycated insulin were not closely linked to either of these parameters. This indicates, perhaps not surprisingly, that the glycation and secretion of insulin from the pancreatic beta cells is a more dynamic process than glycation of haemoglobin which occurs progressively over a much longer period of weeks. However, circulating glycated insulin is much less susceptible to change than the prevailing plasma glucose concentration. Hence, it could be envisaged that circulating glycated insulin will depend not only on the glycaemic environment but also the ability of the beta cells to transport and metabolise glucose to reactive phosphorylated forms at the intracellular sites of (pro)insulin synthesis and storage $[1,2]$. Additionally, the secretory activity and 
competency of the beta cells together with metabolic clearance rate will also determine the rates of delivery and removal of glycated insulin from the circulation.

In conclusion this study describes increased concentrations of plasma glycated insulin in Type 2 diabetic subjects. We speculate that the combined effects of glucose toxicity and beta-cell failure [10], determine the total plasma concentration of glycated insulin in individual patients depending on the spectrum of their current disease.

Acknowledgements. These studies were supported in part by The Wellcome Trust, Diabetes UK, Research and Development Office of HPSS of Northern Ireland, and the University of Ulster research strategic funding.

\section{References}

1. Abdel-Wahab YHA, O’Harte FPM, Ratcliff H, McClenaghan NH, Barnett CR, Flatt PR (1996) Glycation of insulin in the islets of Langerhans of normal and diabetic animals. Diabetes 45:1489-1496

2. Abdel-Wahab YHA, O'Harte FPM, Barnett CR, Flatt PR (1997) Characterization of insulin glycation in insulinsecreting cells maintained in tissue culture. J Endocrinol 152:59-67
3. Abdel-Wahab YHA, O'Harte FPM, Boyd AC, Barnett CR, Flatt PR (1997) Glycation of insulin results in reduced biological activity in mice. Acta Diabetol 34:265-270

4. Boyd AC, Abdel-Wahab YHA, McKillop AM et al. (2000) Impaired ability of glycated insulin to regulate plasma glucose and stimulate glucose transport and metabolism in mouse abdominal muscle. Biochim Biophys Acta 1523: $128-134$

5. O'Harte FPM, Boyd AC, McKillop AM et al. (2000) Structure, antihyperglycemic activity and cellular actions of a novel di-glycated human insulin. Peptides 21:1519-1526

6. Hunter SJ, Boyd AC, O'Harte FPM et al. (2003) Demonstration of glycated insulin in human diabetic plasma and decreased biological activity by euglycemic-hyperinsulinemic clamp technique in man. Diabetes 52:492-498

7. O'Harte FPM, Højrup P, Barnett CR, Flatt PR (1996) Identification of the site of glycation of human insulin. Peptides 17:1323-1330

8. McKillop AM, McCluskey JT, Boyd AC, Mooney MH, Flatt PR, O'Harte FPM (2000) Production and characterization of specific antibodies for evaluation of glycated insulin in plasma and biological tissues. J Endocrinol 167:153-163

9. McKillop AM, Mooney MH, Harriott P, Flatt PR, O'Harte FPM (2001) Evaluation of glycated insulin in diabetic animals using immunocytochemistry and radioimmunoassay. Biochem Biophys Res Comm 286:524-528

10. Flatt PR, Abdel-Wahab YHA, Boyd AC, Barnett CR, O'Harte FPM (1997) Pancreatic B-cell dysfunction and glucose toxicity in non-insulin-dependent diabetes. Proc Nutr Soc 56:243-262 